\title{
RESEARCH
}

Open Access

\section{Multi-level predictors of psychological problems among methadone maintenance treatment patients in difference types of settings in Vietnam}

Tuan Anh Le ${ }^{1,2}$, Mai Quynh Thi Le 1 , Anh Duc Dang ${ }^{1}$, Anh Kim Dang ${ }^{3}$, Cuong Tat Nguyen ${ }^{3 *}$, Hai Quang Pham³, Giang Thu Vư ${ }^{4}$, Chi Linh Hoang ${ }^{5}$, Tung Thanh Tran ${ }^{4}$, Quan-Hoang Vuong ${ }^{6,7}$, Tung Hoang Tran ${ }^{8}$, Bach Xuan Tran ${ }^{2,9}$, Carl A. Latkin ${ }^{9}$ Cyrus S. H. Ho ${ }^{10}$ and Roger C. M. Ho $0^{5,11,12}$

\begin{abstract}
Background: Methadone, a long-acting opioid agonist maintenance treatment (MMT) is used to treat opioid addiction by preventing opioid withdrawal and reducing cravings. However, it is important to note that mental conditions may persist, or even remain undetected while methadone maintenance treatment is ongoing. This study aimed to examine the level of psychological problems among MMT patients at public and private health facilities and identify associated factors.

Method: From January to September 2018, a cross-sectional study was performed in Nam Dinh province, one of the largest epicenters providing HIV/AIDS surveillance and treatment services in the North of Vietnam. 395 male respondents currently receiving MMT agreed to participate in a face-to-face interview. Depression, Anxiety and Stress Scale-21 (DASS-21) were used to assess psychological problems among patients.

Results: The percentage of patients suffering from mild to extremely severe anxiety was the highest among psychological problems (18\%). $2.8 \%$ of participants had mild depressive symptoms and the percentage of those having mild or moderate stress was approximately 4\%. In addition, the longer treatment duration, the lower mental health scores regarding three types of psychological problems. Respondents who received MMT services in public health facilities were more likely to have a higher score of all psychological problems. Participants who lived with partners or spouse, having higher monthly family income had a lower likelihood of having severe depression and stress status. Freelancers or blue-collars/farmers had lower score of depression and anxiety compared to people being unemployed.
\end{abstract}

Conclusion: This study suggests that among our sample, MMT patients receiving treatment in public health facilities might have higher rate of psychological problems, including depression, anxiety, and stress than that of those in the private health facility. These results highlight the necessity of taking psychological counseling adequately for MMT patients and psychological assessment should be prioritized in the early stage of treatment.

Keywords: Psychological, Depression, Anxiety, Stress, Methadone, Vietnam

\footnotetext{
* Correspondence: cuong.ighi@gmail.com

${ }^{3}$ Institute for Global Health Innovations, Duy Tan University, Postal address:

No. 73 Hoang Cau street, Hanoi, Da Nang, Vietnam

Full list of author information is available at the end of the article
}

(C) The Author(s). 2019 Open Access This article is distributed under the terms of the Creative Commons Attribution 4.0 International License (http://creativecommons.org/licenses/by/4.0/), which permits unrestricted use, distribution, and reproduction in any medium, provided you give appropriate credit to the original author(s) and the source, provide a link to the Creative Commons license, and indicate if changes were made. The Creative Commons Public Domain Dedication waiver (http://creativecommons.org/publicdomain/zero/1.0/) applies to the data made available in this article, unless otherwise stated. 


\section{Background}

Methadone Maintenance Treatment (MMT) is a long-term or permanent treatment, which replaces opioids by other substitutes to mitigate physical and psychosocial hardships for patients [1]. Psychiatric disorders have been cited as a significant barrier for individuals to optimally adhere to opioid-dependent treatments. Drug users suffering from psychological health issues have a higher risk of having lower quality of life [2, 3], suicide attempts $[4,5]$ and an even higher rate of mortality [6]. Mental health problems can be considered as driving force in diminishing MMT treatment outcomes such as higher rate of involving in HIV-related risk behaviors [7], interfering with therapeutic compliance with MMT and increasing retention in methadone treatment [8]. Thus, identifying and giving treatments of psychiatric co-morbidities for opioid-addicted patients is crucial to enhance the efficacy of MMT programs.

Evidence in the literature shows that there is a considerable prevalence of MMT patients experiencing psychological problems in which depression and anxiety are overwhelming disorders [9, 10]. A study conducted in China revealed that $57.5 \%$ of MMT users reported to suffer from depressive symptoms, and more than one in four $(25.8 \%)$ had suicidal ideation [11]. In term of depression, a study of Weissman et al. showed that approximately one-third of MMT patients in the community had moderately to severely depression [12], 50\% of MMT patients were found to experience depression based on study of Peles et al. [13], while the rate of lifetime depression prevalence among opioid dependence patients engaging in treatment programs ranged from 20 to $50 \%$ [14].

Notably, the satisfaction of medical services is also considered as a factor related to the mental health status of patients [15]. In order to meet the demand of patients and increase the accessibility of healthcare services, private health facilities also provide MMT treatment for drug users. Public health facility is referred to have a better quality of treatment including licensed and certified medical staff [16], higher diagnostic accuracy [17], better adherence to medical management standards [18] and higher rates of treatment success [19]. On the other hand, private health facility has succeeded in providing a better quality of services, for example, reducing the waiting time [20], improving hospitality from providers [21] and lowering the proportion of patients experiencing stigma and discrimination [22].

The expansion of the MMT program in Vietnam has increased rapidly in recent years. Since the first
MMT clinic introduced in 2008, the government of Vietnam has made great commitment to expanding the MMT program to cover a large number of drug users nationwide [23, 24]. The Ministry of Health in Vietnam also emphasizes the need for psychological healthcare when receiving MMT [25]. Prior studies have assessed the prevalence of psychiatric problems among MMT patients, ranged from 26.8 to $43.1 \%$. $[6,22]$. However, there is little evidence taking account of the impact of different types of MMT outpatient clinics. Therefore, this study aimed to examine the level of psychological problems among MMT patients at public and private health facilities and other factors contributing to a higher risk of suffering from these psychological problems.

\section{Methods}

Study setting and subjects

We conducted a cross-sectional study from January 2018 to September 2018 in Nam Dinh province. Nam Dinh is one of the largest epicenters offering MMT services in the North of Vietnam. The study settings took place in three MMT clinics (Giao Thuy district health center, Dai Dong private health facility and Giao Thuy center for social evils prevention). We selected the clinics based on two eligibility criteria [1] providing methadone treatment services following the official guidelines of the Ministry of Health in Vietnam and [2] the period of offering Methadone treatment services was at least 12 months.

We used convenience sampling technique to recruit participants. Participants were chosen based on four eligibility criteria, which were [1] being at least 18 years old; [2] undergoing MMT services of settings mentioned above; [3] agreeing to participate in the study and [4] being able to answer questions from data collectors. A total of 395 respondents agreed to take part in the study. The percentage of patients in each health facility was 49.4\% (Dai Dong private health facility), 25.3\% (Giao Thuy district health center) and 25.3\% (Giao Thuy center for social evils prevention).

\section{Measure and instruments}

20-min face-to-face interviews were carried out to collect data. The interviewers were well-trained researchers. Medical staffs in the clinics were not invited to participate in data collection in order to avoid social desirability bias. Participants were asked to involve in the study when they attended these clinics for treatment or counseling services. Eligible respondents were identified based on the feedback from medical staffs. To secure participants' 
confidentiality, the interviews occurred in a small private counseling room. Participants could take part in the study after being introduced the study objectives, benefits, drawbacks and provided verbal informed consent.
A pilot survey was conducted prior to the main study among 40 respondents with different social characteristics, including ages, employment and educational level to test and refine the questionnaire. Minor changes regarding wording were made based on the feedback of

Table 1 Socio-economic characteristics of respondents

\begin{tabular}{|c|c|c|c|c|c|c|c|}
\hline \multirow[t]{2}{*}{ Characteristics } & \multicolumn{2}{|c|}{ Private facility } & \multicolumn{2}{|c|}{ State facility } & \multicolumn{2}{|l|}{ Total } & \multirow[t]{2}{*}{$P$-value } \\
\hline & $n$ & $\%$ & $n$ & $\%$ & $n$ & $\%$ & \\
\hline Total & 195 & 49.4 & 200 & 50.6 & 395 & 100 & \\
\hline \multicolumn{8}{|l|}{ Age group } \\
\hline Under 30 & 29 & 14.9 & 19 & 9.5 & 48 & 12.2 & \multirow[t]{4}{*}{$0.03^{*}$} \\
\hline $30-40$ & 89 & 45.6 & 80 & 40.0 & 169 & 42.8 & \\
\hline $41-50$ & 60 & 30.8 & 66 & 33.0 & 126 & 31.9 & \\
\hline Above 50 & 17 & 8.7 & 35 & 17.5 & 52 & 13.2 & \\
\hline \multicolumn{8}{|l|}{ Education } \\
\hline Less than secondary & 33 & 16.9 & 33 & 16.5 & 66 & 16.7 & \multirow[t]{3}{*}{$0.94^{*}$} \\
\hline Secondary school & 118 & 60.5 & 119 & 59.5 & 237 & 60 & \\
\hline More than secondary & 44 & 22.6 & 48 & 24 & 92 & 23.3 & \\
\hline \multicolumn{8}{|l|}{ Marital status } \\
\hline Single & 38 & 19.5 & 29 & 14.5 & 67 & 17 & \multirow[t]{3}{*}{$0.07^{*}$} \\
\hline Live with partners/spouse & 150 & 76.9 & 154 & 77 & 304 & 77 & \\
\hline Divorced/widow & 7 & 3.6 & 17 & 8.5 & 24 & 6.1 & \\
\hline \multicolumn{8}{|l|}{ Occupation } \\
\hline Unemployment & 13 & 6.7 & 20 & 10 & 33 & 8.4 & \multirow[t]{5}{*}{$0.06^{*}$} \\
\hline Freelancer & 63 & 32.3 & 76 & 38 & 139 & 35.2 & \\
\hline Blue collar/farmer & 45 & 23.1 & 47 & 23.5 & 92 & 23.3 & \\
\hline Business & 11 & 5.6 & 17 & 8.5 & 28 & 7.1 & \\
\hline Others & 63 & 32.3 & 40 & 20 & 103 & 26.1 & \\
\hline \multicolumn{8}{|l|}{$\begin{array}{l}\text { Quintile average } \\
\text { family income }\end{array}$} \\
\hline Quintile 1 & 39 & 20 & 41 & 20.5 & 80 & 20.3 & \multirow[t]{5}{*}{$0.89^{*}$} \\
\hline Quintile 2 & 37 & 19 & 45 & 22.5 & 82 & 20.8 & \\
\hline Quintile 3 & 42 & 21.5 & 39 & 19.5 & 81 & 20.5 & \\
\hline Quintile 4 & 43 & 22.1 & 39 & 19.5 & 82 & 20.8 & \\
\hline Quintile 5 & 34 & 17.4 & 36 & 18 & 70 & 17.7 & \\
\hline Ever injected drugs & 121 & 62.1 & 131 & 65.5 & 252 & 63.8 & $0.48^{*}$ \\
\hline Alcohol drink & 114 & 58.5 & 97 & 48.5 & 211 & 53.4 & $0.05^{*}$ \\
\hline Smoke & 163 & 83.6 & 157 & 78.5 & 320 & 81 & $0.20^{*}$ \\
\hline \multirow[t]{2}{*}{ Concurrent drug use } & 15 & 7.7 & 8 & 4 & 23 & 5.8 & \multirow[t]{2}{*}{$0.12^{*}$} \\
\hline & Median & IQR & Median & IQR & Median & IQR & \\
\hline Age & 38 & $33-44$ & 41 & $34-48$ & 39 & $33-46$ & $0.01^{\#}$ \\
\hline Monthly family income (USD) & 344 & $215-430$ & 301 & $215-430$ & 344 & $215-430$ & $0.50^{\#}$ \\
\hline Age of onset of drug use & 25 & $20-30$ & 25 & $21-31$ & 25 & $20-31$ & $0.05^{\#}$ \\
\hline MMT duration (years) & 2 & $1-5$ & 3 & $2-6$ & 3 & $1-5$ & $0.02^{\#}$ \\
\hline
\end{tabular}

*Chi square test, "Mann-Whitney rank sum test 
participants. A structured questionnaire was applied to the following information:

\section{Socioeconomic characteristics}

Participants self-reported general information, including age, marital status, occupation, educational level and monthly income.

\section{Mental health status}

In order to assess the mental health status among participants, we used the Depression, Anxiety, and Stress Scale-21 (DASS-21). This tool consists of 21 items, which measure three sub-scales of emotional states, including depression, anxiety, and stress. Each sub-scale contains 7 questions and the answer for each question ranges from 0 (Did not apply to me at all) to 3 (Applied to me very much, or most of the time). Participants were asked to indicate the presence of a symptom over the past week. Scores for three emotional states were calculated by summing the points for the relevant items (question 3, 5, 10, $13,16,17,21$ for depression; question $1,6,8,11$, $12,14,18$ for stress; question $2,4,7,9,15,19,20$ for anxiety) and double up. There were 5 levels for the cut-off point based on DASS-21 scoring containing: normal, mild, moderate, severe, extremely severe. The DASS can be a useful assessment of disturbance, either the level of severity of patients' symptoms or how the patient's response to treatment [26].

\section{Health risk behavior}

Participants were asked about whether they currently drink alcohol, smoke tobacco or use drugs. In term of quality of life, "How your quality of life change between before and after having MMT service?" was also mentioned in the questionnaire. Participants also reported their HIV-infection status.

\section{Methadone maintenance treatment-related-characteristics}

Participants self-reported their overall assessment regarding the quality of MMT service in the health facility where they attended and their satisfaction for traveling to MMT facility to take pills. Level of adherence to MMT was self-assessed using a Likert scale, including 5 options from "Very good" to "Very bad". Moreover, a 100-point visual analog scale (VAS) was also employed to detect patients' adherence, with a score range from 0 "incompletely adherence" to 100 "completely adherence". The threshold for optimal adherence was $95 \%$.

Table 2 MMT - related characteristic of participants

\begin{tabular}{|c|c|c|c|c|c|c|c|}
\hline \multirow[t]{2}{*}{ Characteristics } & \multicolumn{2}{|c|}{ Private facility } & \multicolumn{2}{|c|}{ State facility } & \multicolumn{2}{|c|}{ Total } & \multirow[t]{2}{*}{$P$-value } \\
\hline & $\bar{n}$ & $\%$ & $n$ & $\%$ & $n$ & $\%$ & \\
\hline \multicolumn{8}{|l|}{$\begin{array}{l}\text { Quality of life change } \\
\text { after using MMT }\end{array}$} \\
\hline Better & 185 & 94.9 & 192 & 96.0 & 377 & 95.4 & \multirow[t]{2}{*}{0.59} \\
\hline Unchanged & 10 & 5.1 & 8 & 4.0 & 18 & 4.6 & \\
\hline \multicolumn{8}{|l|}{ HIV test results } \\
\hline Negative & 178 & 92.7 & 169 & 89.9 & 347 & 91.3 & \multirow[t]{3}{*}{0.47} \\
\hline Positive & 7 & 3.7 & 7 & 3.7 & 14 & 3.7 & \\
\hline Unknown & 7 & 3.7 & 12 & 6.4 & 19 & 5.0 & \\
\hline \multicolumn{8}{|l|}{ MMT adherence VAS } \\
\hline Optimal adherence & 96 & 49.2 & 75 & 37.5 & 171 & 43.3 & \multirow[t]{2}{*}{0.02} \\
\hline Suboptimal adherence & 99 & 50.8 & 125 & 62.5 & 224 & 56.7 & \\
\hline \multicolumn{8}{|l|}{ Receiving support for MMT } \\
\hline $\begin{array}{l}\text { Health workers } \\
\text { at MMT facility }\end{array}$ & 97 & 49.7 & 66 & 33.0 & 163 & 41.3 & $<0.01$ \\
\hline Relatives in family & 167 & 85.6 & 140 & 70.0 & 307 & 77.7 & $<0.01$ \\
\hline Peer in MMT & 41 & 21.0 & 26 & 13.0 & 67 & 17.0 & 0.03 \\
\hline Neighbors/other acquaintances & 9 & 4.6 & 7 & 3.5 & 16 & 4.1 & 0.57 \\
\hline
\end{tabular}




\section{Social/family support}

To identify the support from social and family, we asked participants about whether they received the support during MMT duration.

\section{Statistical analysis}

STATA version 12 (Stata Corp. LP, College Station, United States of America) were used to analyze data. A Chi-square test, a Mann Whitney test and a Kruskal-Wallis test were used for analyzing demographic characteristics of participants as well as health risk behaviors, depression situation. Multivariate Tobit regression was applied to examine factors associated with a psychological problem. The Tobit regression model is designed to assess linear relationships between variables when dependent variables censored from below and above [27]. In this study, each of the psychological subscales may range between 0 and 42 . To identify the reduced regression model, we applied a forward stepwise selection strategy with the threshold of less than 0.2. A $p$-value $<0.05$ was considered as statistical significance.

\section{Ethics approval}

Ethics approval was reviewed and granted by the Institutional Review Board of National Institute of Hygiene and Epidemiology.

\section{Results}

Table 1 presents the socioeconomic characteristics of participants. The percentage of participants from 30 to 40 years old was highest (42.8\%). A high proportion of participants had secondary school education $(60.0 \%)$, lived with partners or spouse (77.0\%) and were freelancers (35.2\%). Prevalence of smoking was found to be high in the study areas (81\%) and more than half of participants $(53.4 \%)$ reported that they consume alcohol. Approximately two-thirds of participants had a history of injecting

Table 3 Psychological problems among MMT patients

\begin{tabular}{|c|c|c|c|c|c|c|c|}
\hline \multirow[t]{2}{*}{ Characteristics } & \multicolumn{2}{|c|}{ Private facility } & \multicolumn{2}{|c|}{ Public facility } & \multicolumn{2}{|l|}{ Total } & \multirow[t]{2}{*}{$P$-value } \\
\hline & $n$ & $\%$ & $n$ & $\%$ & $n$ & $\%$ & \\
\hline Total & 195 & 49.4 & 200 & 50.6 & 395 & 100.0 & \\
\hline \multicolumn{8}{|l|}{ Depression } \\
\hline Normal & 187 & 95.9 & 193 & 96.5 & 380 & 96.2 & \multirow[t]{5}{*}{$0.71^{*}$} \\
\hline Mild & 6 & 3.1 & 5 & 2.5 & 11 & 2.8 & \\
\hline Moderate & 1 & 0.5 & 1 & 0.5 & 2 & 0.5 & \\
\hline Severe & 0 & 0.0 & 1 & 0.5 & 1 & 0.3 & \\
\hline Extremely severe & 1 & 0.5 & 0 & 0.0 & 1 & 0.3 & \\
\hline \multicolumn{8}{|l|}{ Anxiety } \\
\hline Normal & 170 & 87.2 & 154 & 77.0 & 324 & 82.0 & \multirow[t]{5}{*}{$0.05^{*}$} \\
\hline Mild & 13 & 6.7 & 21 & 10.5 & 34 & 8.6 & \\
\hline Moderate & 9 & 4.6 & 23 & 11.5 & 32 & 8.1 & \\
\hline Severe & 2 & 1.0 & 2 & 1.0 & 4 & 1.0 & \\
\hline Extremely severe & 1 & 0.5 & 0 & 0.0 & 1 & 0.3 & \\
\hline \multicolumn{8}{|l|}{ Stress } \\
\hline Normal & 188 & 96.4 & 191 & 95.5 & 379 & 96.0 & \multirow[t]{4}{*}{$0.88^{*}$} \\
\hline Mild & 6 & 3.1 & 8 & 4.0 & 14 & 3.5 & \\
\hline \multirow[t]{2}{*}{ Moderate } & 1 & 0.5 & 1 & 0.5 & 2 & 0.5 & \\
\hline & Mean & SD & Mean & SD & Mean & SD & \\
\hline \multicolumn{8}{|c|}{ DASS-21 sub-scale score } \\
\hline Depression & 1.2 & 3.2 & 1.7 & 3.0 & 1.5 & 3.1 & $<0.01^{\#}$ \\
\hline Anxiety & 2.9 & 3.9 & 4.2 & 3.8 & 3.6 & 3.9 & $<0.01^{\#}$ \\
\hline Stress & 1.7 & 3.4 & 2.5 & 3.6 & 2.1 & 3.5 & $<0.01^{\#}$ \\
\hline
\end{tabular}

*Chi square test, ${ }^{\#}$ Mann-Whitney rank sum test 
drug $(63.8 \%)$ and only $5 \%$ of participants were concurrently using drug.

According to Table 2, almost all of participants reported that their life changed better after using MMT (95.4\%). Only 3.7\% were HIV-infected. 43.3\% of participants reported optimal MMT adherence and about $77 \%$ of responders received support from family during MMT treatment.

Table 3 highlights the psychological characteristics of participants according to different types of health facilities. Regarding depression, only $2.8 \%$ of participants had mild depressive symptoms and about $1 \%$ of participants suffered from moderate, severe and extremely severe depression. About $8 \%$ of respondents underwent mild (8.6\%) or moderate anxiety (8.1\%). The percentage of those having mild or moderate stress was approximately $4 \%$. The mean score of all psychological dimension among participants using services in MMT public facilities was significantly higher than those who use private MMT service. These differences were statistically significant $(p<0.05)$.

Figure 1 indicated that the longer of treatment duration, the lower mental health scores regarding three types of psychological problems. Anxiety score and stress score a significant decrease during the time of treatment.

The results of the regression models were displayed in Table 4. Respondents who received MMT services in public health facilities were more likely to have a higher score of all psychological problems. Participants who living with partners or spouse had a lower likelihood of having more severe depression and stress status than those who are single. People having higher monthly family income and health workers at MMT facility as supporters have a negative association with DASS-21 score. Compared to being unemployed, freelancer or blue-collar/farmer
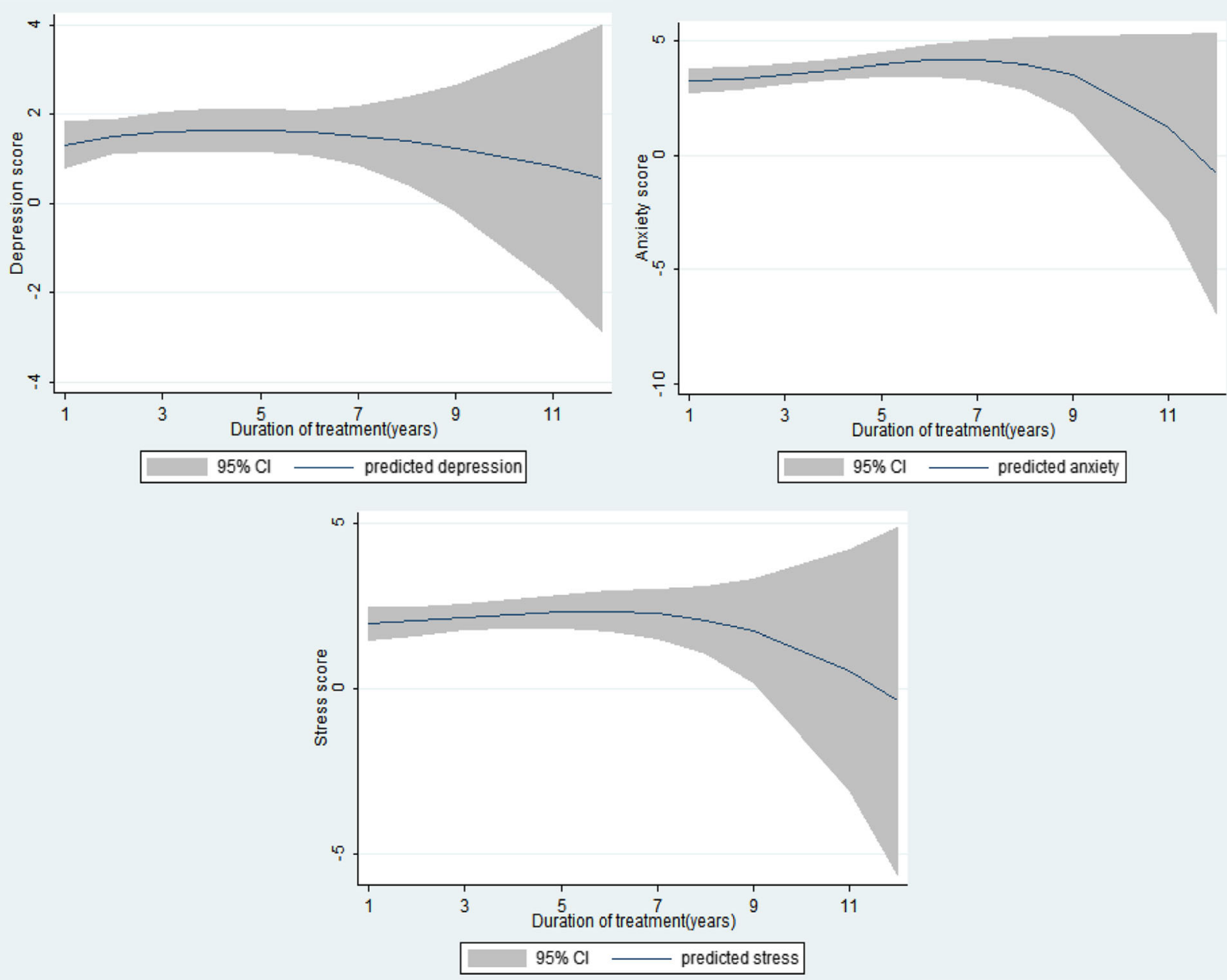

Fig. 1 Mean DASS 21 Depression score for duration of MMT. Abbreviation: DASS 21 - the Depression, Anxiety, and Stress Scales 
Table 4 Factors associated with mental health of MMT patients

\begin{tabular}{|c|c|c|c|c|c|c|}
\hline \multirow[t]{2}{*}{ Characteristics } & \multicolumn{2}{|c|}{ Depression } & \multicolumn{2}{|l|}{ Anxiety } & \multicolumn{2}{|l|}{ Stress } \\
\hline & Coef. & $95 \% \mathrm{Cl}$ & Coef. & $95 \% \mathrm{Cl}$ & Coef. & $95 \% \mathrm{Cl}$ \\
\hline \multicolumn{7}{|l|}{$\begin{array}{l}\text { Marital status } \\
\text { (vs Single) }\end{array}$} \\
\hline $\begin{array}{l}\text { Live with } \\
\text { partners/spouse }\end{array}$ & $-3.67^{*}$ & $-5.75 ;-1.60$ & & & $-2.62^{*}$ & $-4.27 ;-0.97$ \\
\hline Divorced/widow & -3.15 & $-6.81 ; 0.50$ & & & & \\
\hline \multicolumn{7}{|l|}{$\begin{array}{l}\text { Occupation } \\
\text { (vs Unemployment) }\end{array}$} \\
\hline Freelancer & $-2.33^{*}$ & $-4.24 ;-0.41$ & $-2.00^{*}$ & $-3.35 ;-0.64$ & & \\
\hline Blue collar/farmer & & & $-1.73^{*}$ & $-3.25 ;-0.21$ & & \\
\hline Business & & & & & 2.74 & $-0.12 ; 5.59$ \\
\hline Others & 1.94 & $-0.14 ; 4.01$ & & & $3.13^{*}$ & $1.42 ; 4.83$ \\
\hline \multicolumn{7}{|l|}{$\begin{array}{l}\text { Quintile monthly } \\
\text { family income } \\
\text { (vs Poorest) }\end{array}$} \\
\hline Poor & & & 1.16 & $-0.28 ; 2.60$ & & \\
\hline Rich & -1.93 & $-4.02 ; 0.17$ & & & -1.73 & $-3.61 ; 0.15$ \\
\hline Richest & $-3.46^{*}$ & $-5.84 ;-1.09$ & & & $-2.19^{*}$ & $-4.22 ;-0.17$ \\
\hline Smoke (Yes vs no) & -1.40 & $-3.44 ; 0.63$ & -1.35 & $-2.85 ; 0.14$ & & \\
\hline $\begin{array}{l}\text { Concurrent drug use } \\
\text { (Yes vs no) }\end{array}$ & & & 2.07 & $-0.45 ; 4.58$ & & \\
\hline $\begin{array}{l}\text { Ever injected drugs } \\
\text { (Yes vs no) }\end{array}$ & & & & & 1.18 & $-0.35 ; 2.72$ \\
\hline $\begin{array}{l}\text { MMT model (Public facility } \\
\text { vs private facility) }\end{array}$ & $2.98^{*}$ & $1.24 ; 4.72$ & $2.04^{*}$ & $0.85 ; 3.23$ & $2.09^{*}$ & $0.62 ; 3.57$ \\
\hline $\begin{array}{l}\text { Quality of life } \\
\text { during receiving } \\
\text { MMT treatment (Unchanged vs better) }\end{array}$ & $4.85^{*}$ & $1.04 ; 8.66$ & & & 3.12 & $-0.46 ; 6.70$ \\
\hline \multicolumn{7}{|l|}{ Supportive person in MMT (Yes vs no) } \\
\hline None & -2.03 & $-4.18 ; 0.13$ & & & & \\
\hline Health workers at MMT facility & -1.45 & $-3.26 ; 0.37$ & $-2.00^{*}$ & $-3.23 ;-0.77$ & $-2.39^{*}$ & $-3.92 ;-0.87$ \\
\hline Neighbors/other acquaintances & & & 2.51 & $-0.48 ; 5.51$ & & \\
\hline \multicolumn{7}{|l|}{ HIV test results (vs Negative) } \\
\hline Unknown & & & & & 2.25 & $-0.84 ; 5.35$ \\
\hline
\end{tabular}

were associated with a lower score of depression and anxiety. By contrast, having the unchanged quality of life after using treatment had a positive association with anxiety and stress sub-scale score.

\section{Discussion}

This study presents empirical evidence for the psychological issues among patients receiving methadone maintenance treatment in different types of settings in Vietnam. The higher percentage of psychological problems including depression, anxiety, and stress was found among participants receiving treatment in public health facilities compared to those in private health facilities. In addition, predictors of mental health problems which based on multivariate regression model presented possible methods for identifying and preventing MMT patients who are at high risk of suffering from those psychological problems. The results highlight the need for implementing further mental healthcare services for MMT patients.

In this study, the rate of anxiety was the highest among psychological problems, which is consistent with the previous research [9]. In addition, more 
than two-thirds of opioid-dependent adults may undergo anxiety disorder during their lifetime [28]. The percentages of anxiety and depression in our study are lower than these rates in previous studies conducted among MMT patients in the rural parts and mountainous, remote areas of Vietnam $[6,22]$. The difference can be explained by the fact that patients who live in mountainous areas have poorer access to healthcare services due to the lack of transportation, inadequate infrastructure, and high travel expense [29]. Moreover, a higher rate of experiencing stigma among MMT patients living in mountainous settings may contribute to the higher prevalence of psychological distress among those subjects [30]. The percentage of having psychological problems among MMT patients in other countries including the United States of America and Indonesia is higher than our finding, which may be due to the difference of culture [31-33]. The previous study also revealed that the lifetime rate of psychological disorders of Asia nations was lower than that of Western countries [34].

Interestingly, participants receiving MMT services in public health facilities had higher scores of DASS-21 in all measured psychological dimensions, compared to those having treatment in private health facilities. The poor performance of public sector services may result in the demand for generating private health facilities and private sectors account for $60 \%$ of outpatient contacts in Vietnam [16]. In term of accessibility, patients attending in private hospital tended to have shorter waiting time and reported better hospitality from providers compared to public facilities [20, 21]. Regarding responsiveness, the overwhelming workload may reduce the quality of public health facilities [35], for example, inadequate mental health counseling sessions [36] or lack of diagnosis explanation, especially which related to psychological problems [37]. In addition, stigmatization, a factor that can put MMT patients at higher risk of mental health issues and non-adherence to treatment [22], is also more common in public health facilities [38].

Our study also found that MMT patients with prolonged treatment duration greater than 9 years had lower scores in all psychological aspects, suggesting a lower risk of suffering from mental health problems. This situation can be explained by the fact that at the initial of receiving MMT, patients have to adapt to strict adherence [39] and face with securing their financial and social wellbeing during treatment duration $[40,41]$. In this study, being unemployed and at poorer quintile groups also put MMT patients at higher risk of suffering from mental health problems. Moreover, long-term methadone patients, especially who involved in therapy continuously over many years, understand very well their treatment program with valuable insights on achieving reasonable goals and expectations [42]. Therefore, they may become more complacent because of either their physical health or mental health status recovered [39].

Several implications can be drawn from this study. First, screening for identifying psychological problems should be conducted in MMT clinics, especially in public health facilities. Patients found to suffer from mental health problems should take psychological counseling adequately. Second, taking account of the above discussions, facilitating employment and financial support will contribute to reducing the risk of undergoing psychological problems and should be implemented as a part of the primary care for MMT patients in Vietnam. Third, the reduction in DASS-21 observed in prolonged MMT duration suggests that more psychological assessment should be prioritized in the early stage of treatment. Integrating both physical and psychological care into MMT clinics and enhancing further related services to primary healthcare should be taken into account, especially when patients are at the initial period of the MMT program.

The strength of this study is using a validated international instrument (DASS-21) to assess psychological issues among MMT patients, which helps to improve the comparability between other studies worldwide and this study. However, several limitations should be acknowledged. First, a cross-sectional study design may limit the ability for establishing causal relationships among variables. Second, convenience sampling techniques and small sample size may decrease the capacity of generalizing the findings to the whole MMT patient population as well as reducing statistical power. Lastly, the information obtained by selfreported questionnaires may lead to recall bias and be influenced by social desirability.

\section{Conclusions}

This study suggests that MMT patients receiving treatment in public health facilities might have a higher rate of psychological problems including depression, anxiety, and stress than that of those in the private health facility. Multiple factors predicting MMT patients who were at high risk of suffering from those psychological problems were also found. These results highlight the necessity of taking psychological counseling adequately for MMT patients and psychological assessment should be prioritized in the early stage of treatment. 


\section{Abbreviations}

MMT: Methadone Maintenance Treatment; VAS: Visual analog scale

\section{Acknowledgements}

The authors would like to acknowledge supports by the Giao Thuy district health center, Dai Dong private health facility and Giao Thuy center for social evils prevention, Nam Dinh province for the implementation of the study.

\section{Authors' contributions}

TAL, MQTL, ADD, AKD, CTN, HQP, GTV, CLH, TIT, QHV, THT, BXT, CAL, CSHH, $\mathrm{RCMH}$ conceived of the study, and participated in its design and implementation and wrote the manuscript. TAL, MQTL, ADD, analyzed the data. BXT, GHH, CAL, CSHH, RCMH helped to draft the manuscript. All authors read and approved the final manuscript.

\section{Funding}

There was no funding for this analysis.

\section{Availability of data and materials}

The data that support the findings of this study are available from the Institutional Review Board of National Institute of Hygiene and Epidemiology but restrictions apply to the availability of these data, which were used under license for the current study, and so are not publicly available. Data are however available from the authors upon reasonable request and with permission of from the Institutional Review Board of National Institute of Hygiene and Epidemiology.

\section{Ethics approval and consent to participate}

Ethics approval was reviewed and granted by the Institutional Review Board of National Institute of Hygiene and Epidemiology. All participants were informed of the study's purpose and were asked to provide written informed consent prior to the initiation of the study. Participants were informed that they could withdraw at any time. All participants were also informed that their information was kept confidential.

\section{Consent for publication}

Not applicable.

\section{Competing interests}

The authors declare that they have no competing interests.

\section{Author details}

${ }^{1}$ National Institute of Hygiene and Epidemiology, Hanoi 100000, Vietnam. ${ }^{2}$ Institute for Preventive Medicine and Public Health, Hanoi Medical University, Hanoi 100000, Vietnam. ${ }^{3}$ Institute for Global Health Innovations, Duy Tan University, Postal address: No. 73 Hoang Cau street, Hanoi, Da Nang, Vietnam. ${ }^{4}$ Center of Excellence in Evidence-based Medicine, Nguyen Tat Thanh University, Ho Chi Minh City 700000, Vietnam. ${ }^{5}$ Center of Excellence in Behavior Medicine, Nguyen Tat Thanh University, Ho Chi Minh 700000, Vietnam. ${ }^{6}$ Centre for Interdisciplinary Social Research, Phenikaa University, Yen Nghia, Ha Dong, Hanoi 100803, Vietnam. ${ }^{7}$ Faculty of Economics and Finance, Phenikaa University, Yen Nghia, Ha Dong, Hanoi 100803, Vietnam. ${ }^{8}$ Institute of Orthopaedic and Trauma Surgery, Vietnam - Germany Hospital, Hanoi 100000, Vietnam. 'Bloomberg School of Public Health, Johns Hopkins University, Baltimore, MD 21205, USA. ${ }^{10}$ Department of Psychological Medicine, National University Hospital, Singapore 119074, Singapore. ${ }^{11}$ Department of Psychological Medicine, Yong Loo Lin School of Medicine, National University of Singapore, Singapore 117599, Singapore. ${ }^{12}$ Biomedical Global Institute of Healthcare Research \& Technology (BIGHEART), National University of Singapore, Singapore 117599, Singapore.

Received: 29 April 2019 Accepted: 20 August 2019

Published online: 18 September 2019

\section{References}

1. Parvaresh N, Masoudi A, Majidi-Tabrizi S, Mazhari S. The correlation between methadone dosage and comorbid psychiatric disorders in patients on methadone maintenance treatment. Addict Health. 2012;4(1-2):1-8.

2. Carpentier PJ, Krabbe PF, van Gogh MT, Knapen LJ, Buitelaar JK, de Jong CA. Psychiatric comorbidity reduces quality of life in chronic methadone maintained patients. Am J Addict. 2009;18(6):470-80.
3. Yen CN, Wang CS, Wang TY, Chen HF, Chang HC. Quality of life and its correlates among heroin users in Taiwan. Kaohsiung J Med Sci. 2011;27(5):177-83.

4. Chen VC, Lin TY, Lee CT, Lai TJ, Chen H, Ferri CP, et al. Suicide attempts prior to starting methadone maintenance treatment in Taiwan. Drug Alcohol Depend. 2010;109(1-3):139-43.

5. Huang $\mathrm{CL}$, Lee $\mathrm{CW}$. Factors associated with mortality among heroin users after seeking treatment with methadone: a population-based cohort study in Taiwan. J Subst Abus Treat. 2013;44(3):295-300.

6. Tran BX, Nguyen LH, Nong VM, Nguyen CT, Phan HT, Latkin CA. Behavioral and quality-of-life outcomes in different service models for methadone maintenance treatment in Vietnam. Harm Reduct J. 2016:13:4.

7. Lai HM, Cleary M, Sitharthan T, Hunt GE. Prevalence of comorbid substance use, anxiety and mood disorders in epidemiological surveys, 1990-2014: a systematic review and meta-analysis. Drug Alcohol Depend. 2015;154:1-13.

8. Baharudin A, Mislan N, Ibrahim N, Sidi H, Nik Jaafar NR. Depression in male patients on methadone maintenance therapy. Asia-Pacific psychiatry : official journal of the Pacific Rim College of Psychiatrists. 2013;5(Suppl 1):67-73.

9. Jiao M, Gu J, Xu H, Hao C, Lau JT, Mo P, et al. Resilience associated with mental health problems among methadone maintenance treatment patients in Guangzhou. China AIDS care. 2017;29(5):660-5.

10. Zhang $X, X u H, G u$ J, Lau JT, Hao C, Zhao Y, et al. Depression, suicidal ideation, and related factors of methadone maintenance treatment users in Guangzhou. China AIDS care. 2016;28(7):851-6.

11. Liang T, Liu EW, Zhong H, Wang B, Shen LM, Wu ZL. Reliability and validity of addiction severity index in drug users with methadone maintenance treatment in Guizhou province. China Biomed Environ Sci. 2008;21(4):308-13.

12. Weissman MM, Slobetz F, Prusoff B, Mezritz M, Howard P. Clinical depression among narcotic addicts maintained on methadone in the community. Am J Psychiatry. 1976;133(12):1434-8.

13. Peles E, Schreiber S, Naumovsky Y, Adelson M. Depression in methadone maintenance treatment patients: rate and risk factors. J Affect Disord. 2007; 99(1-3):213-20.

14. Nunes E, Quitkin F, Brady R, Post-Koenig T. Antidepressant treatment in methadone maintenance patients. J Addict Dis. 1994:13(3):13-24.

15. Williams $J$, Rheingold AA. Barriers to care and service satisfaction following homicide loss: associations with mental health outcomes. Death Stud. 2015;39(1-5):12-8.

16. Basu S, Andrews J, Kishore S, Panjabi R, Stuckler D. Comparative performance of private and public healthcare systems in low- and middleincome countries: a systematic review. PLoS Med. 2012;9(6):e1001244.

17. Auer C, Lagahid JY, Tanner M, Weiss MG. Diagnosis and management of tuberculosis by private practitioners in Manila, Philippines. Health policy (Amsterdam, Netherlands). 2006:77(2):172-81.

18. Ogwal-Okeng JW, Obua C, Waako P, Aupont O, Ross-Degnan D. A comparison of prescribing practices between public and private sector physicians in Uganda. East Afr Med J. 2004;Suppl:S12-6

19. Bisson GP, Frank I, Gross R, Lo Re V 3rd, Strom JB, Wang X, et al. Outof-pocket costs of HAART limit HIV treatment responses in Botswana's private sector. AIDS. 2006;20(9):1333-6.

20. Brugha R, Pritze-Aliassime S. Promoting safe motherhood through the private sector in low- and middle-income countries. Bull World Health Organ. 2003;81(8):616-23.

21. Gilson L, Alilio M, Heggenhougen K. Community satisfaction with primary health care services: an evaluation undertaken in the Morogoro region of Tanzania. Soc Sci Med (1982. 1994;39(6):767-80.

22. Nguyen LH, Tran BX, Nguyen HLT, Nguyen CT, Hoang CD, Le HQ, et al. Psychological distress among methadone maintenance patients in Vietnamese mountainous areas. AIDS Behav. 2017;21(11):3228-37.

23. Vietnam Go. Vietnam AIDS response Progress report 2012. Hanoi: National Committee for AIDS, Drugs and Prostitution Prevention and Control; 2012

24. Nguyen TT, Nguyen LT, Pham MD, Vu HH, Mulvey KP. Methadone maintenance therapy in Vietnam: an overview and scaling-up plan. Adv Prev Med. 2012;2012:732484.

25. Ministry of Health. Guideline for Substance abuse treatment using methadone, Decision No 3140/QD-BYT (2010).

26. Le MTH, Tran TD, Holton S, Nguyen HT, Wolfe R, Fisher J. Reliability, convergent validity and factor structure of the DASS-21 in a sample of Vietnamese adolescents. PLoS One. 2017;12(7):e0180557.

27. Tran BX, Dang AK, Truong NT, Ha GH, Nguyen HLT, Do HN, et al. Depression and Quality of Life among Patients Living with HIV/AIDS in 
the Era of Universal Treatment Access in Vietnam. Int J Environ Res Public Health. 2018;15(12). https://doi.org/10.3390/ijerph15122888.

28. Grella CE, Karno MP, Warda US, Niv N, Moore AA. Gender and comorbidity among individuals with opioid use disorders in the NESARC study. Addict Behav. 2009;34(6-7):498-504.

29. Tran $B X$, Nguyen $L H$, Nong VM, Nguyen $C T$. Health status and health service utilization in remote and mountainous areas in Vietnam. Health Qual Life Outcomes. 2016;14:85.

30. Van Nguyen $H$, Nguyen HL, Mai HT, Le HQ, Tran BX, Hoang CD, et al. Stigmatization among methadone maintenance treatment patients in mountainous areas in northern Vietnam. Harm Reduct J. 2017;14(1):1.

31. Grant BF, Stinson FS, Dawson DA, Chou SP, Dufour MC, Compton W, et al. Prevalence and co-occurrence of substance use disorders and independent mood and anxiety disorders: results from the National Epidemiologic Survey on alcohol and related conditions. Arch Gen Psychiatry. 2004;61(8):807-16.

32. Rosen D, Smith ML, Reynolds CF 3rd. The prevalence of mental and physical health disorders among older methadone patients. Am J Geriatr Psychiatry. 2008;16(6):488-97.

33. Brienza RS, Stein MD, Chen M, Gogineni A, Sobota M, Maksad J, et al. Depression among needle exchange program and methadone maintenance clients. J Subst Abus Treat. 2000;18(4):331-7.

34. Steel Z, Marnane C, Iranpour C, Chey T, Jackson JW, Patel V, et al. The global prevalence of common mental disorders: a systematic review and metaanalysis 1980-2013. Int J Epidemiol. 2014:43(2):476-93.

35. Govindasamy D, Ford N, Kranzer K. Risk factors, barriers and facilitators for linkage to antiretroviral therapy care: a systematic review. AIDS. 2012;26(16):2059-67.

36. Shet A, DeCosta A, Heylen E, Shastri S, Chandy S, Ekstrand M. High rates of adherence and treatment success in a public and public-private HIV clinic in India: potential benefits of standardized national care delivery systems. BMC Health Serv Res. 2011:11:277.

37. Bhatia J, Cleland J. Health care of female outpatients in south-Central India: comparing public and private sector provision. Health Policy Plan. 2004;19(6):402-9.

38. Moyo F, Chasela C, Brennan AT, Ebrahim O, Sanne IM, Long L, et al. Treatment outcomes of HIV-positive patients on first-line antiretroviral therapy in private versus public HIV clinics in Johannesburg. South Africa Clin Epidemiol. 2016;8:37-47.

39. Tran BX, Nguyen LT, Nguyen NH, Hoang QV, Hwang J. Determinants of antiretroviral treatment adherence among HIV/AIDS patients: a multisite study. Glob Health Action. 2013;6:19570.

40. Tran BX, Ohinmaa A, Duong AT, Do NT, Nguyen LT, Nguyen QC, et al. Changes in drug use are associated with health-related quality of life improvements among methadone maintenance patients with HIV/AIDS. Qual Life Res. 2012;21(4):613-23.

41. Tran BX, Nguyen LH, Ohinmaa A, Maher RM, Nong VM, Latkin CA. Longitudinal and cross sectional assessments of health utility in adults with HIV/AIDS: a systematic review and meta-analysis. BMC Health Serv Res. 2015;15:7.

42. Marion IJ. Methadone treatment at forty. Sci Pract Perspect. 2005;3(1):25-31.

\section{Publisher's Note}

Springer Nature remains neutral with regard to jurisdictional claims in published maps and institutional affiliations.

Ready to submit your research? Choose BMC and benefit from:

- fast, convenient online submission

- thorough peer review by experienced researchers in your field

- rapid publication on acceptance

- support for research data, including large and complex data types

- gold Open Access which fosters wider collaboration and increased citations

- maximum visibility for your research: over $100 \mathrm{M}$ website views per year

At BMC, research is always in progress.

Learn more biomedcentral.com/submissions 